\title{
Rehabilitation Exercise and psycholoGical support After covid-19 InfectioN' (REGAIN): a structured summary of a study protocol for a randomised controlled trial
}

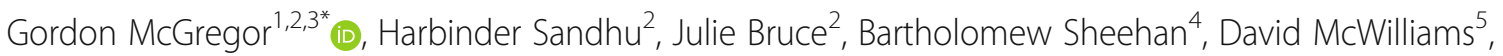
Joyce Yeung ${ }^{2,6}$, Christina Jones ${ }^{7}$, Beatriz Lara ${ }^{8}$, Jessica Smith², Chen Ji ${ }^{2}$, Elaine Fairbrother ${ }^{9}$, Stuart Ennis ${ }^{1,2}$, Peter Heine ${ }^{1,2}$, Sharisse Alleyne ${ }^{2}$, Jonathan Guck ${ }^{2}$, Emma Padfield ${ }^{2}$, Rachel Potter ${ }^{2}$, James Mason ${ }^{10}$, Ranjit Lall ${ }^{2}$, Kate Seers ${ }^{11}$ and Martin Underwood ${ }^{2}$

\begin{abstract}
Objectives: The primary objective is to determine which of two interventions: 1) an eight week, online, homebased, supervised, group rehabilitation programme (REGAIN); or 2) a single online session of advice (best-practice usual care); is the most clinically and cost-effective treatment for people with ongoing COVID-19 sequelae more than three months after hospital discharge.
\end{abstract}

Trial design: Multi-centre, 2-arm (1:1 ratio) parallel group, randomised controlled trial with embedded process evaluation and health economic evaluation.

Participants: Adults with ongoing COVID-19 sequelae more than three months after hospital discharge Inclusion criteria: 1) Adults $\geq 18$ years; 2) $\geq 3$ months after any hospital discharge related to COVID-19 infection, regardless of need for critical care or ventilatory support; 3 ) substantial (as defined by the participant) COVID-19 related physical and/or mental health problems; 4) access to, and able/supported to use email and internet audio/ video; 4) able to provide informed consent; 5) able to understand spoken and written English, Bengali, Gujarati, Urdu, Punjabi or Mandarin, themselves or supported by family/friends.

Exclusion criteria: 1) exercise contraindicated; 2) severe mental health problems preventing engagement; 3) previous randomisation in the present study; 4) already engaged in, or planning to engage in an alternative NHS rehabilitation programme in the next 12 weeks; 5) a member of the same household previously randomised in the present study.

(Continued on next page)

\footnotetext{
* Correspondence: gordon.mcgregor@uhcw.nhs.uk;

gordon.mcgregor@warwick.ac.uk

${ }^{1}$ Department of Cardiopulmonary Rehabilitation, Centre for Exercise \& Health,

University Hospitals Coventry \& Warwickshire NHS Trust, Coventry, UK

${ }^{2}$ Warwick Clinical Trials Unit, Warwick Medical School, University of Warwick,

Coventry, UK

Full list of author information is available at the end of the article
}

(c) The Author(s). 2021, corrected publication 2021. Open Access This article is licensed under a Creative Commons Attribution 4.0 International License, which permits use, sharing, adaptation, distribution and reproduction in any medium or format, as long as you give appropriate credit to the original author(s) and the source, provide a link to the Creative Commons licence, and indicate if changes were made. The images or other third party material in this article are included in the article's Creative Commons licence, unless indicated otherwise in a credit line to the material. If material is not included in the article's Creative Commons licence and your intended use is not permitted by statutory regulation or exceeds the permitted use, you will need to obtain permission directly from the copyright holder. To view a copy of this licence, visit http://creativecommons.org/ licenses/by/4.0/. The Creative Commons Public Domain Dedication waiver (http://creativecommons.org/publicdomain/zero/1. 0/) applies to the data made available in this article, unless otherwise stated in a credit line to the data. 
(Continued from previous page)

Intervention and comparator: Intervention 1: The Rehabilitation Exercise and psycholoGical support After covid-19 InfectioN (REGAIN) programme: an eight week, online, home-based, supervised, group rehabilitation programme. Intervention 2: A thirty-minute, on-line, one-to-one consultation with a REGAIN practitioner (best-practice usual care).

Main outcomes: The primary outcome is health-related quality of life (HRQOL) - PROMIS ${ }^{\circledR} 29+2$ Profile v2.1 (PROPr) - measured at three months post-randomisation.

Secondary outcomes include dyspnoea, cognitive function, health utility, physical activity participation, posttraumatic stress disorder (PTSD) symptom severity, depressive and anxiety symptoms, work status, health and social care resource use, death - measured at three, six and 12 months post-randomisation.

Randomisation: Participants will be randomised to best practice usual care or the REGAIN programme on a 1:1.03 basis using a computer-generated randomisation sequence, performed by minimisation and stratified by age, level of hospital care, and case level mental health symptomatology.

Once consent and baseline questionnaires have been completed by the participant online at home, randomisation will be performed automatically by a bespoke web-based system.

Blinding (masking): To ensure allocation concealment from both participant and REGAIN practitioner at baseline, randomisation will be performed only after the baseline questionnaires have been completed online at home by the participant. After randomisation has been performed, participants and REGAIN practitioners cannot be blind to group allocation. Follow-up outcome assessments will be completed by participants online at home.

Numbers to be randomised (sample size): A total of 535 participants will be randomised: 263 to the bestpractice usual care arm, and 272 participants to the REGAIN programme arm.

Trial Status: Current protocol: Version 3.0 (27th October 2020) Recruitment will begin in December 2020 and is anticipated to complete by September 2021.

Trial registration: ISRCTN:11466448, 23rd November 2020

Full protocol: The full protocol Version 3.0 (27th October 2020) is attached as an additional file, accessible from the Trials website (Additional file 1). In the interests of expediting dissemination of this material, the familiar formatting has been eliminated; this Letter serves as a summary of the key elements of the full protocol.

The study protocol has been reported in accordance with the Standard Protocol Items: Recommendations for Clinical Interventional Trials (SPIRIT) guidelines.

Keywords: COVID-19, randomised controlled trial, protocol, rehabilitation, exercise, psychological support, mental health, physical health, online

\section{Supplementary Information}

The online version contains supplementary material available at https://doi. org/10.1186/s13063-020-04978-9.

\section{Additional file 1 .}

\section{Acknowledgements}

With thanks to Juwairia Sajid, Pritpal Klear, Alastair Canaway and Katie Booth.

\section{Authors' contributions}

GM and MU were responsible for the trial concept. GM, HS, JB, BS, DM, JY, $C J, B L, C J i, E F, J M, R L, K S, M U$, are grant holders. All authors contributed to the study protocol: GM, SE, PH (clinical exercise rehabilitation); MU, JB (clinical trials); HS, BS (psychology/psychiatry); JY, DM, CJ (critical care medicine and rehabilitation); BL (respiratory medicine); RL, CJi (statistics); JM (health economics); KS (process evaluation, qualitative), RP (PPI); EF (patient representative); JS, SA, JG, EP (trial management). All authors read and approved the final version of the manuscript.

\section{Funding}

The study is funded by the National Institute of Health Research COVID-19 Recovery and Learning Programme (NIHR132046). The views expressed are those of the author(s) and not necessarily those of the NIHR or the Department of Health and Social Care. The study sponsor and funder have no role in the study design, data acquisition, data analysis or manuscript preparation.

\section{Availability of data and materials}

The chief investigator and co-investigators will have access to the final trial dataset. The trial will be reported in accordance with the Consolidated Standards of Reporting Trials (CONSORT) guidelines. Trial results will be published in peer-reviewed open access journals.

Requests for data sharing will be reviewed on an individual basis by the chief investigator in consultation with the trial management group and trial steering committee, after publication of the final trial results. The study will comply with the good practice principles for sharing individual participant data from publicly funded clinical trials and data sharing will be undertaken in accordance with the required regulatory requirements.

\section{Ethics approval and consent to participate}

The study was approved by East of England, Cambridge South Research Ethics Committee: reference 20/EE/0235; and the HRA/HCRW on $6^{\text {th }}$ November 2020. IRAS project ID: 288362.

The authors certify that this trial has received ethical approval from the appropriate ethical committee as described above. Informed consent to participate in the study will be obtained from all participants.

\section{Consent for publication}

Not applicable

\section{Competing interests}

$\mathrm{GM}, \mathrm{MU}, \mathrm{JB}, \mathrm{HS}, \mathrm{KS}$ are chief or co-investigator on multiple previous and current research grants from the UK National Institute for Health Research. 
GM, JB and HS are chief or co-investigator on a current British Heart Foundation grant.

GM \& SE are Clinical Exercise Physiologists delivering cardiopulmonary rehabilitation for the NHS and are directors of Atrium Health Ltd, a cardiopulmonary rehabilitation provider. DM is a physiotherapist delivering post-ICU rehabilitation for the NHS. HS is director of Health Psychology Services Ltd, a private health psychology provider.

MU is an investigator on Arthritis Research UK and Australian NHMRC grants. $\mathrm{He}$ is an NIHR Senior Investigator. He has received travel expenses for speaking at conferences from the professional organisations hosting the conferences. He is a director and shareholder of Clinvivo Ltd that provides electronic data collection for health services research. He is part of an academic partnership with Serco Ltd, funded by the European Social Fund, related to return to work initiatives. He is a co-investigator on two NIHR funded studies receiving additional support from Stryker Ltd. He has accepted honoraria for teaching/lecturing from consortium for advanced research training in Africa. Until March 2020 he was an editor of the NIHR journal series, and a member of the NIHR Journal Editors Group, for which he received a fee.

JB is chief or co-investigator on Diabetes UK grants. She has received travel expenses for speaking at conferences from the professional organisations hosting these conferences.

KS was a member of the NIHR HS\&DR Board from 2010-2018.

\section{Author details}

'Department of Cardiopulmonary Rehabilitation, Centre for Exercise \& Health, University Hospitals Coventry \& Warwickshire NHS Trust, Coventry, UK.

${ }^{2}$ Warwick Clinical Trials Unit, Warwick Medical School, University of Warwick, Coventry, UK. ${ }^{3}$ Centre for Sport, Exercise \& Life Sciences, Coventry University, Coventry, UK. ${ }^{4}$ Coventry \& Warwickshire Partnership Trust, Coventry, UK. ${ }^{5}$ Centre for Care Excellence, University Hospitals Coventry \& Warwickshire NHS Trust, Coventry, UK. ${ }^{6}$ Department of Anaesthesia and Critical Care, University Hospitals Birmingham NHS Foundation Trust, Birmingham, UK. ${ }^{7}$ ICUSteps, Kemp House, London, UK. ${ }^{8}$ Department of Respiratory Medicine, University Hospitals Coventry \& Warwickshire NHS Trust, Coventry, UK. ${ }^{9}$ Patient \& Public Involvement Representative, Coventry, UK. ${ }^{10} \mathrm{Centre}$ for Health Economics at Warwick, Warwick Medical School, University of Warwick, Coventry, UK. ${ }^{11}$ Warwick Research in Nursing, Warwick Medical School, University of Warwick, Coventry, UK.

Received: 10 December 2020 Accepted: 15 December 2020 Published online: 06 January 2021

\section{Publisher's Note}

Springer Nature remains neutral with regard to jurisdictional claims in published maps and institutional affiliations.

Ready to submit your research? Choose BMC and benefit from:

- fast, convenient online submission

- thorough peer review by experienced researchers in your field

- rapid publication on acceptance

- support for research data, including large and complex data types

- gold Open Access which fosters wider collaboration and increased citations

- maximum visibility for your research: over $100 \mathrm{M}$ website views per year

At $\mathrm{BMC}$, research is always in progress.

Learn more biomedcentral.com/submissions 